\title{
ASSESSMENT OF ROCK SLOPE STABILITY USING REMOTE SENSING TECHNIQUE IN THE GOLD COAST AREA, AUSTRALIA
}

\author{
I. GRATCHEV \\ Griffith School of Engineering, Griffith University, Australia, ivangratchev@gmail.com
}

A. SHOKOUHI

Griffith School of Engineering, Griffith University, Australia

D.H. KIM

Griffith School of Engineering, Griffith University, Australia,donghyun.kim3@griffithuni.edu.au

D. STEAD

Simon Fraser University, Canada, dstead@sfu.ca

A. WOLTER

Simon Fraser University, Canada, awolter@sfu.ca

Rock falls and landslides along major roads cause significant damage to infrastructure in the Gold Coast area, Australia. Current methods of hazard assessment, which mostly include field mapping and data collection for site characterization, are inherently labor intensive and subject to bias due to safety issues and time constrains. However, many of these problems have recently been addressed through the development and deployment of digital imaging technology based on photogrammetry. This method involves the use of high-resolution digital stereo-photographs, from which a three-dimensional image of the slope can be constructed. Such images can highlight the surface texture of slopes and identify potentially unstable zones, thus providing engineers with valuable information regarding the slope design. Photogrammetry is still a relatively new remote sensing technique in Australia and has mostly been used in the mining industry. Little has been done to study the feasibility of its application in civil engineering to solve geotechnical problems related to the stability of natural slopes and road cuts. This paper presents the results of a pilot study aimed at assessing the stability of rock slopes in the Gold Coast area. Field surveys including photogrammetry were performed to study the geological settings of the sites, and characterize the slope's topography and type of discontinuities. Based on the 3-D models, the potentially unstable zones were identified, and slope stability analysis of those areas was performed. The obtained results indicated that photogrammetry can be a helpful tool in assessing geohazard related to slope stability problems.

\section{INTRODUCTION}

Geohazards associated with ground movements can affect the safety of humans and cause damage to infrastructure. Rock falls in open pit mining, landslides along major roads, cliff failures and erosion along the shore line are examples of natural hazard that need to be properly assessed to minimize potential damage from their occurrence. Current methods of hazard assessment, which mostly include field mapping and data collection for site characterization, are inherently labour intensive and subject to bias due to safety issues and time constrains. This limits the extent of data collected, which affects the accuracy of subsequent interpretation, analysis and the overall 
engineering design. However, many of these problems have recently been addressed through the development of digital imaging technology based on photogrammetry.

This method involves the use of high-resolution digital stereo-photographs, from which a threedimensional image of the slope can be constructed using the specialized software "Sirovision" (Poropat [3]). The three-dimensional image can highlight the surface texture of the slope that can be estimated from close-up digital photographs. Potentially unstable zones of such slopes can be easily identified and its stability can be readily assessed to provide engineers with valuable information regarding the slope design. In addition, this method has several advantages such as reduction in time and labor costs, as well as it provides opportunities to survey inaccessible steep rock slopes.

Despite the number of advantages, photogrammetry is still a relatively new remote sensing technique in Australia, which is mostly used in the mining industry. Little has been done to study the feasibility of its application to solve civil engineering problems. This work explores this area by conducting a case study that involved a road cut along one of the major roads in the Gold Coast area.

\section{STUDY AREA}

Field surveys were conducted on a slope cut along the Beaudesert-Nerang Road that connected the Gold Coast with the Tambourine Mountain area. The length of this slope was about $200 \mathrm{~m}$ with the height varying from 8-10 m (Fig. 1a). This slope frequently experienced slope stability problems, especially during long periods of rain. A recent wedge failure (Fig. 1a) prompted researchers from Griffith University to investigate the stability issue of this part of the road.

A field survey revealed that the site was comprised of argillite and greywacke of the NeranleighFernvale Beds (Willmott [7]; Shokouhi et al. [5]). The rocks were heavily weathered, folded and steeply inclined. Argillite, which is hardened and slightly recrystalized shale, was fine-grained rock, bedding (Fig. 1b), and fractured in many exposures. The greywacke was mostly coarsegrained sediment of dark grey color. The in-situ strength characteristics of these rocks were measured by performing a number of Schmidt hammer tests. Some samples were also collected for laboratory examination including a series of point load tests.

\section{APPLICATION OF PHOTOGRAMMETRY TO CHARACTERIZE SLOPE FEATURES}

Field set-up and georeferencing

A professional Nikon camera (model D7000) and lens of $24 \mathrm{~mm}$ focal length were used to photograph four different sections of the slope. Each section was photographed from two points, with the distance between the camera positions being equal to $1 / 10$ the distance from the camera to the slope (Atkinson [1]). Georeferencing was performed for each photo by determining the coordinates of the left camera position (using a GPS device), and measuring its bearing (azimuth) to the centre of slope (using a geological compass) (Sturzenegger [6]). 

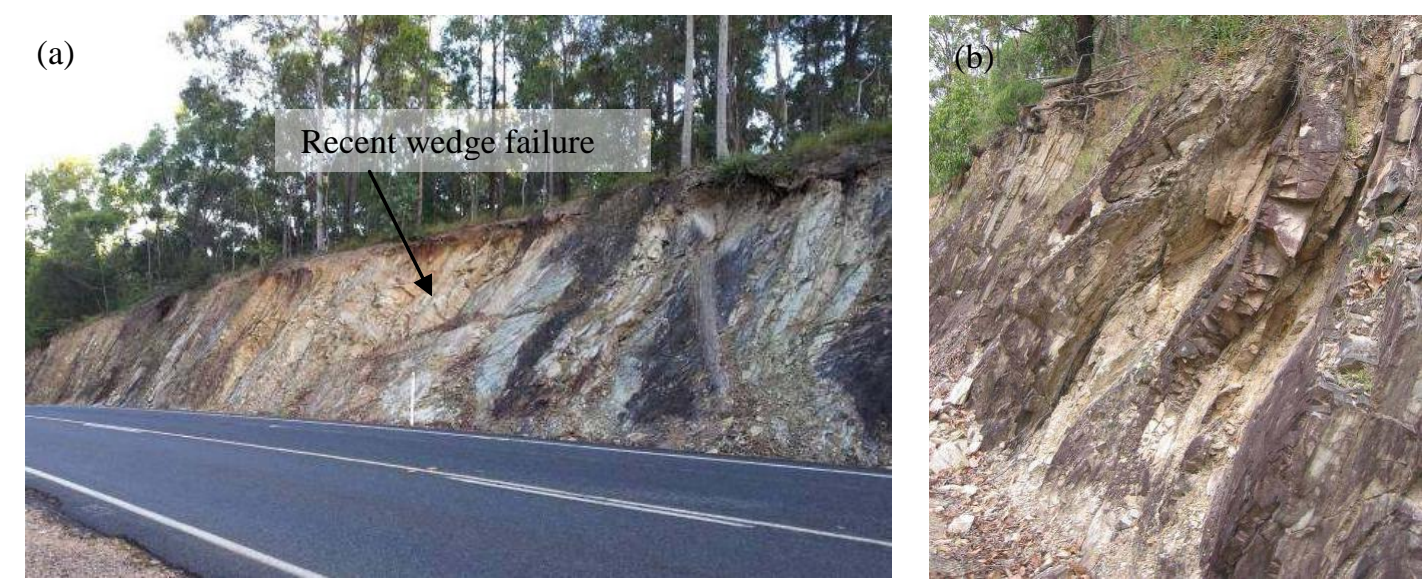

Figure 1. The study area: a) a rock slope comprised of argillite and greywacke of the NeranleighFernvale Beds; $b$ ) bedding of the argillite.

\section{D-models and slope mapping}

After 3D-models were built for each slope section (Fig. 2a) using the "Sirovision" computer code, mapping of the major slope features, including discontinuities, were performed as shown in Fig. 2b. The size of blocks, type and characteristics of discontinuities including dip and dip direction, were identified and recorded.

\section{Precision of the obtained results}

To establish whether the photogrammetry technique can produce accurate measurements of dip and dip direction of discontinuities, comparisons between these variables obtained by 1) means of a geological compass, and 2) photogrammetry surveys were made. The results for six control points are given in Table 1. Analysis of the obtained data yields the mean error for the dip measurements of $1.4^{\circ}$, and for dip direction $-2.8^{\circ}$. Although the photogrammetry technique is not standardized, it seems that the results obtained through photogrammetry can be considered as acceptable due to the relatively small error compared those obtained by means of a standard geological compass.

Table 1. Values of dip and dip direction measured using two techniques.

\begin{tabular}{|c|c|c|c|c|}
\hline \multirow{2}{*}{ Control point No. } & \multicolumn{2}{|c|}{ Direct measurement } & \multicolumn{2}{|c|}{ Photogrammetry } \\
\cline { 2 - 5 } & Dip $\left(^{\circ}\right)$ & Dip direction $\left(^{\circ}\right)$ & Dip $\left(^{\circ}\right)$ & Dip direction $\left(^{\circ}\right)$ \\
\hline 1 & 59 & 64 & 56.5 & 66.4 \\
2 & 57 & 66 & 52.2 & 64.9 \\
3 & 55 & 60 & 53.1 & 59.7 \\
4 & 48 & 56 & 49.9 & 53.4 \\
5 & 29 & 38 & 31.5 & 36.5 \\
6 & 49 & 349 & 45.7 & 335.3 \\
\hline
\end{tabular}


(a)

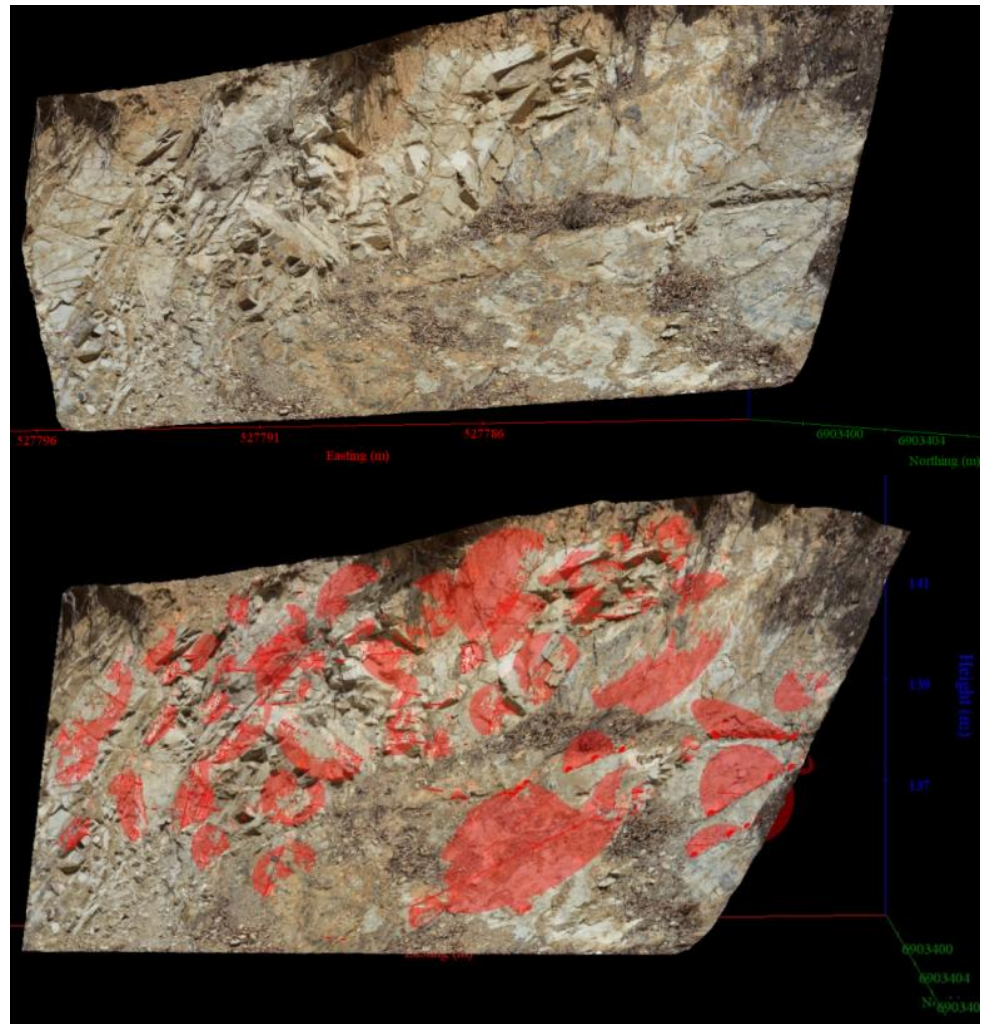

Figure 2. A 3D-model of slope section No. 2 (a), and mapping of major geological structures (b).

\section{Kinematic analysis}

Kinematic analyses, following the procedure described by Goodman [2], were performed to assess the stability of each slope section against toppling, planar and wedge failures. The Rocscience "Dips" computer code (Rocsience [4]) based on the stereonet approach was utilized for this purpose. The values of dip and dip directions for each slope section were exported from the 3Dmodels. To obtain the strength properties of the rocks, a series of point load tests were conducted on rock samples collected from the face of the slope, and the obtained data are plotted in Fig. 3 against the corresponding values of the unconfined compressive strength (UCS). It is evident from this figure that the strength of rocks is rather low, probably due to the high level of weathering. The available literature suggests that the friction angle of heavily weathered rocks such as argillite and sandstone can be assumed to be about $30^{\circ}$, which is a value that was used in this analysis.

Two representative examples of kinematic analysis performed for the slopes section No. 2 are presented in Fig. 4 for toppling failure (a), and planar failure (b). It is evident from Fig. 4a that this part of the slope has a very low probability of toppling as no pole falls inside the "toppling" zone. However, due to the large number of poles located in the "planar" zone (Fig. 4b), the probability of planar failure of this section of the slope appears to be relatively high. 


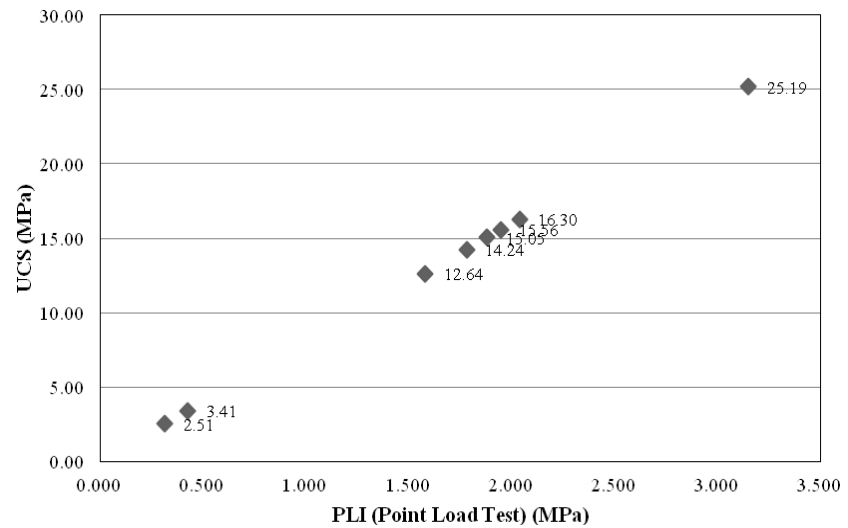

Figure 3. Results from a series of point load tests plotted against the corresponding values of unconfined compressive strength (UCS).
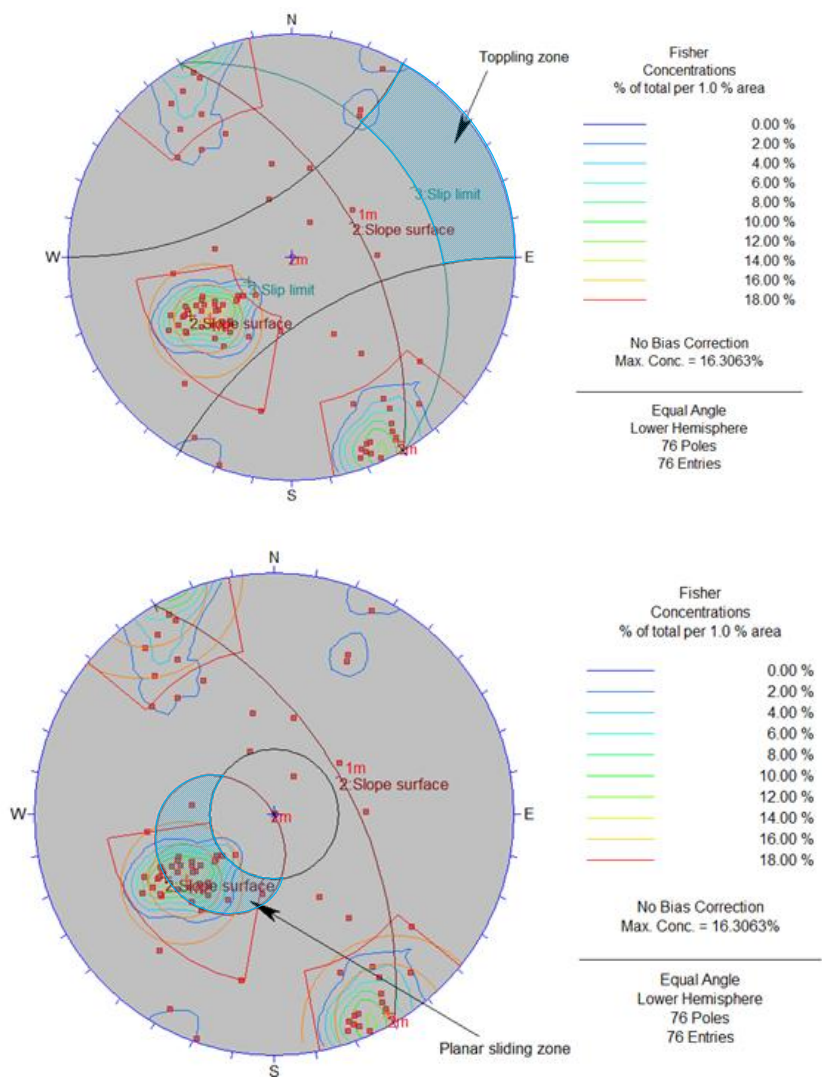

Figure 4. Results of kinematic analysis using the Rocscience "Dips": a) toppling failure, and b) planar failure. 


\section{CONCLUDING REMARKS}

This work investigates the feasibility of using photogrammetry for assessment of rock slope stability in the Gold Coast area. Based on the obtained results, the following conclusions can be drawn:

- The accuracy of the photogrammetry technique to measure the dip and dip direction of discontinuities was examined against the measurement performed by a standard geological compass. The mean errors for dip and dip direction were $1.4^{\circ}$ and $2.8^{\circ}$, respectively, suggesting that photogrammetry can produce measurements with a high level of precision.

- Field observations and the data from a series of point load tests indicated that the rocks were heavily weathered with low values of strength.

- The results of kinematic analyses indicated that there was no risk for toppling failure, but the slope had a high probability for planar sliding failure.

\section{ACKNOWLEDGEMENTS}

The authors acknowledge the valuable help of Mr. George Poropat from CSIRO. This research was supported by the NRG grant from Griffith University, Australia.

\section{REFERENCES}

[1] Atkinson K.B., "Close range photogrammetry and machine vision”, Whittles, (2001).

[2] Goodman R.E., "Introduction to rock mechanics”, Wiley New York, (1989).

[3] Poropat G.V., "Remote 3D mapping of rock mass structure", Proc. 41st US Symposium on Rock Mechanics, Colorado, (2006).

[4] Rocscience, "Dips users`manual”, Rocsience Inc, Canada, (2010).

[5] Shokouhi A., Gratchev I., Charrismanagara A., "Rock slope stability problems in Gold Coast area, Australia", Proc. Second International Conference on Geotechnique, Construction Materials and Environment, Malaysia, (2012).

[6] Sturzenegger M., "Multi-scale characterization of rock mass discontinuities and rock slope geometry using terrestrial remote sensing techniques", PhD Thesis, Simon Fraser University, (2010).

[7] Willmott W., "Rocks and landscape of the Gold coast hinterland, Brisbane", Geological society of Australia, (2010). 